\title{
PaLS Study: How Has the COVID-19 Pandemic Influenced Physical Activity and Nutrition? Observations a Year after the Outbreak of the Pandemic
}

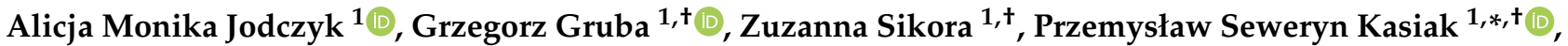 \\ Joanna Gębarowska 1,2, Natalia Adamczyk 1,2, Artur Mamcarz 2,3 (D) and Daniel Śliż 1,2,3,4
}

1 Students' Scientific Group of Lifestyle Medicine, 3rd Department of Internal Medicine and Cardiology, Medical University of Warsaw, 04-749 Warsaw, Poland; alicja.jodczyk@gmail.com (A.M.J.); gregorygpl@gmail.com (G.G.); zznnsikora@gmail.com (Z.S.); gebarowska.joanna@gmail.com (J.G.); adamczyk.natalia1997@gmail.com (N.A.); sliz.daniel@gmail.com (D.Ś.)

2 Polish Society of Lifestyle Medicine, 00-388 Warsaw, Poland; artur.mamcarz@wum.edu.pl

3 3rd Department of Internal Medicine and Cardiology, Medical University of Warsaw, 04-749 Warsaw, Poland

4 School of Public Health, Postgraduate Medical Education Center, 01-813 Warsaw, Poland

* Correspondence: przemyslaw.kasiak1@gmail.com; Tel.: +48-501-168-103

+ Equally contributed as second authors.

Citation: Jodczyk, A.M.; Gruba, G.; Sikora, Z.; Kasiak, P.S.; Gẹbarowska, J.; Adamczyk, N.; Mamcarz, A.; Śliż, D. PaLS Study: How Has the COVID-19 Pandemic Influenced Physical Activity and Nutrition? Observations a Year after the Outbreak of the Pandemic. Int. J. Environ. Res. Public Health 2021, 18, 9632. https://doi.org/10.3390/ ijerph18189632

Academic Editor: Leigh A. Frame

Received: 4 August 2021

Accepted: 7 September 2021

Published: 13 September 2021

Publisher's Note: MDPI stays neutral with regard to jurisdictional claims in published maps and institutional affiliations.

Copyright: (c) 2021 by the authors. Licensee MDPI, Basel, Switzerland. This article is an open access article distributed under the terms and conditions of the Creative Commons Attribution (CC BY) license (https:/ / creativecommons.org/licenses/by/ $4.0 /)$.

\begin{abstract}
The restrictions implemented to prevent the spread of the SARS-CoV-2 virus have impacted the majority of life domains. To evaluate their potential consequences on physical activity (PA) and dietary habits among Polish undergraduates, a survey consisting of the IPAQ-SF, authors' questions based on the Polish National Institute of Public Health recommendations, and authors' questions scaled $-5 / 0 / 5$ on personal opinion was created and administered between 22 February and 3 April 2021. A total of 1323 students met the study conditions (1021 females, 297 males, 5 did not specify gender, mean age: 22 years old $(\mathrm{SD}=4)$, mean $\left.\mathrm{BMI}=22.27 \mathrm{~kg} / \mathrm{m}^{2}(\mathrm{SD}=3.87)\right)$. A total of $27.21 \%$ of students were in the low, $48.53 \%$ in the moderate, and $24.26 \%$ in the high PA group. A total of $71.94 \%$ estimated that the pandemic had a negative impact on their PA, $8.16 \%$ no impact, and $19.9 \%$ a positive impact. A total of $35.5 \%$ had an insufficient intake of vegetables, $34.3 \%$ declared adding salt to meals, and $31.6 \%$ ate animal-based products the majority of days in a week or every day. A total of $51.02 \%$ assessed the impact of the pandemic on their nutrition as negative, $20.11 \%$ did not notice changes, and $28.87 \%$ reported a positive impact on their dietary habits. Most of the students saw harmful pandemic effects on their diet and PA compared to the times before restrictions. This can lead to a higher prevalence of non-communicable diseases (NCDs) in the future.
\end{abstract}

Keywords: physical activity; nutrition; public health; COVID-19 pandemic; lifestyle medicine

\section{Introduction}

The outbreak of the COVID-19 pandemic has forced a change in the ordinary lifestyle of many populations. On 20 March 2020, the government announced the epidemic in Poland [1] and introduced numerous restrictions to limit the spread of the virus: staying at home, quarantine periods, and the closure of fitness clubs, gyms, and swimming pools. At the time, these actions were probably necessary [2,3], but they caused a significant decrease in exercise options and changed dietary habits [4]. Observations and the available literature indicate that these changes affected people's lifestyle and could have an impact on medical problems we will be dealing with in the future [5,6]. Studies from different countries report that home confinement and other imposed safety measures have negatively influenced physical activity (PA) levels among many age groups [7-9], including university students $[10,11]$. In addition, previous research has reported negative changes in dietary patterns $[12,13]$. Studies show that chronic life stress seems to be linked with a greater 
intake of energy- and nutrient-dense foods, especially those with high sugar and fat [14], while also being associated with a higher BMI (Body Mass Index) [15].

The nutrition and level of physical activity of university students were alarming and unsatisfying before the pandemic [16,17]. In previous years, there has been a rise in the westernisation of diet among this population [18]. Moreover, the consumption of meat, animal and vegetable fat (margarine), and sugar [18] increased. Polish university students' diet was characterised by a high intake of cured meat, smoked sausages, hot dogs, white bread, bakery products, butter, fried foods, and energy drinks [17]. What is more, students from Polish universities had the highest scores in the consumption of food of a potentially negative effect on health in comparison to students from Germany and Slovakia [17]. They often skipped breakfast, snacked in between main meals, and had insufficient levels of physical activity $[19,20]$. Data from previous studies show that the large majority of university students failed to meet recommendations on exercise and had inadequate PA levels $[19,21,22]$. Despite being aware of the importance of a proper diet and adequate levels of PA, students did not implement these rules into their lives [17,19].

Physical activity and a healthy diet have numerous benefits on health [23]. A higher adherence to the Mediterranean diet is associated with a lower incidence of type 2 diabetes, a lower incidence/mortality of CVD, and a lower incidence/mortality of cancer [24]. Being physically active improves all-cause mortality, cardiovascular disease mortality, incident hypertension, incident site-specific cancers, incident type 2 diabetes, mental health (reduced symptoms of anxiety and depression), cognitive health, and sleep [25]. Physical inactivity, obesity, and a Western diet are modifiable risk factors of most non-communicable diseases (NCDs) [26]. They increase mortality and cause a loss of disease-free years of life $[27,28]$. They are also associated with a higher risk of community-acquired pneumonia and pneumonia mortality [29]. A combination of a Western diet and physical inactivity results in an increased BMI [30], associated with a higher risk of diabetes, cardiovascular disease, joint disorders (osteoarthritis), and oncogenesis, especially endometrial, breast, ovarian, prostate, liver, gallbladder, kidney, and colon cancers [31]. NCDs are increasing worldwide and within the European region [32,33]. We believe that the COVID-19 pandemic and the lockdown may cause an increase in the number of people suffering from NCDs at a younger age.

Therefore, our study was a part of the PaLS-Pandemic against LifeStyle project, which aimed to evaluate the impact of the lockdown on the lifestyle of Polish university students. We hypothesised that the COVID-19 pandemic would have a negative impact on this population by decreasing their PA level, increasing sedentary behaviour, and causing poorer nutritional habits. To the best of our knowledge, no scientific data regarding the effect of the COVID-19 pandemic on the abovementioned lifestyle areas in the Polish undergraduate population have been reported.

\section{Materials and Methods}

\subsection{Design and Selection of Study Subjects}

A cross-sectional survey was designed and shared via different social media channels and e-mails (e.g., Polish Lifestyle Medicine newsletter, students' university groups, Instagram, Facebook) a year after the outbreak of the pandemic in Poland from 22 February 2021 to 3 April 2021. It was half-term time and the beginning of the second academic semester. Answers were collected with the use of online survey app Google Sheets and converted into Excel file for analysis. Our study had only 2 inclusion criteria. Respondents had to: 1. be a 1st to 6th year of study university student (bachelor's or master's degree studies or equivalent), 2. study at a Polish university. There were no age limitations, but we did not include postgraduate and doctoral students. The requirements were pointed out at the beginning of the questionnaire so that the participants could assess if they fulfilled them or not. Data were collected from 1646 participants, and 1323 of them met all the study conditions. We excluded responders whose answers were unviable (e.g., BMI $=5 \mathrm{~kg} / \mathrm{m}^{2}$ or being physically active for $24 \mathrm{~h}$ /day) or answered "I don't remember" in any of the 
International Physical Activity-Short Form (IPAQ-SF) questions. There were no other exclusion criteria. Data were collected during the semester break and the beginning of the second semester. Figure 1 illustrates the number of excluded students at each part of our two-stage procedure.

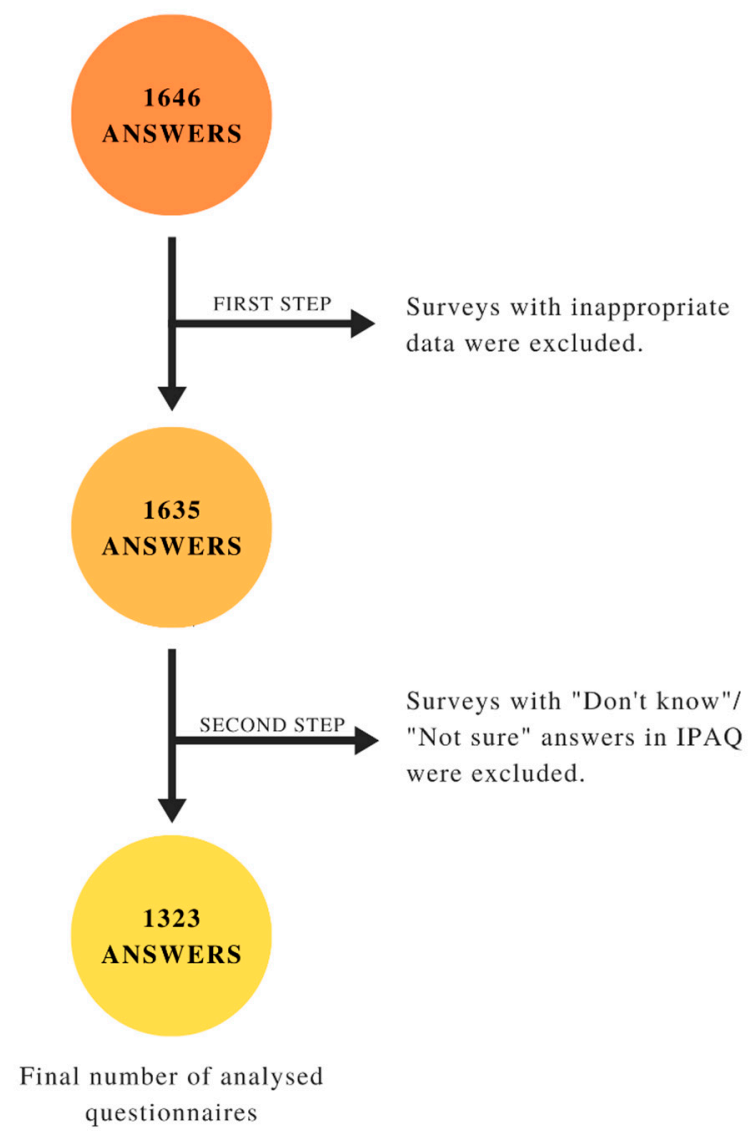

Figure 1. Stepwise data cleaning process.

\subsection{Construction of the Questionnaire}

A statement about the aims of the study and the declaration of anonymity and confidentiality were included in the form. Filling in the questionnaire and clicking the "send" button was tantamount to informed consent to participate in the study (proper information was mentioned at the background of the questionnaire). This study did not require Institutional Review Board approval and a proper judgement was obtained. Sociodemographic data such as age, sex, year of study, and self-reported biometric data height and weight were collected. Participants were asked about their physical activity and sedentary behaviour with questions from the International Physical Activity Questionnaire-Short Form (IPAQ-SF) [34] and eating habits with authors' questions based on Polish National Institute of Public Health recommendations [35]. The survey contained an additional $-5 / 0 /+5$ scaled questions about responders' subjective assessment of the pandemic's impact on their physical activity (PA) and eating habits. Questionnaire form is available in the Supplementary Material.

\subsubsection{IPAQ-SF and Dietary Habits}

The IPAQ- SF was included to estimate the amount of time dedicated to PA per week. The questionnaire is adapted for many populations (including the Polish one). It assesses three specific types of activity: walking and moderate and vigorous intensity. Due to the scoring protocol, data are calculated into MET-minutes/week values [36]. MET (metabolic equivalent) is the specific metabolic equivalent and its values vary for each category of PA (3.3 MET for walking, 4 MET for moderate-intensity PA, and 8 MET for vigorous-intensity 
PA) [37]. To calculate weekly energy expenditure (MET-minutes/week values) for each type of activity, the following formula is used: weekly energy expenditure (MET-min/week) $=$ MET $x$ duration of PA type (minutes) $x$ frequency. Total MET-minutes/week value is a sum of walking MET-min/week, moderate MET-min/week, and vigorous MET-min/week. According to scoring protocol, individuals are divided into PA categories: low, moderate, high. The final question in IPAQ-SF assesses the daily amount of time in a sitting position by obtaining it in hours and minutes.

To assess dietary changes, 12 authors' questions based on the Polish National Institute of Public Health recommendations were designed [35]. Responders were asked about the composition of their meals and the supply of the nutrients (e.g., consumption of vegetables and fruits, unsweetened milk, products containing processed meat, products that are a source of animal fats or trans fatty acids, sweetened beverages or fruit juices instead of water, salt). Additionally, questions about dietary behaviours such as eating in front of electronic screens, paying attention to the nutritional value of buying products, and consuming more meals than before the pandemic were asked. For that part of the survey, participants could choose one of the following responses: once a week and less often, 2-3 times a week, most days of the week, every day. These figures were expressed as a percentage and compared with the Polish National Institute of Public Health recommendations.

\subsubsection{Self-Assessment Question}

Participants matched the level of perceived change resulting from the pandemic in $-5 / 0 /+5$ scaled questions. Answers from -5 to -1 meant that the pandemic had a negative impact, answer 0 meant no effect, and answers from +1 to +5 meant positive impact. It was an additional question in both parts: physical activity and eating habits.

\subsection{Data Analysis}

All statistical analyses were performed using the statistical software STATISTICA (version 13.3, StatSoft Polska Sp.z. o.o., Kraków, Poland) and SPSS Statistics (version 27.0, IBM, Chicago, IL, USA). Participants were classified into subgroups (age, sex, year of study, studying at medical or non-medical university). Based on mean answers and statistical test scores, the direction of correlation (positive or negative) was assessed. To calculate the correlation between studying at medical university/BMI, gender/PA level, BMI/PA level, studying at medical university/PA, and BMI/dietary habits, the U Mann-Whitney test was performed. Correlations between the year of study and reported level of perceived pandemic impact (declared answers in $-5 / 0 /+5$ questions) were calculated based on the H Kruskal-Wallis test. For analysis of the correlation between studying at medical university/dietary habits, higher MET-min/week value, and reported pandemic impact in self-assessment $(-5 / 0 /+5)$ scale, rho-Spearman test and r-Pearson test were performed. Findings on eating habits were converted into percentage values and compared to Polish National Institute of Public Health recommendations.

\section{Results}

\subsection{Sociodemographic Characteristics and BMI Index}

A total number of 1646 Polish students participated in the study, and 1323 of them met the study conditions (1021 females, 297 males, 5 did not specify gender). The mean age of the participants was 22 years old $(\mathrm{SD}=4)$, and the median was 22 years old. The demographic characteristics of participants including gender, BMI category, university, and year of study are presented in Table 1 . Mean BMI was $22.27 \mathrm{~kg} / \mathrm{m}^{2}$ ( $\mathrm{SD}=3.87$ ); median $21.48 \mathrm{~kg} / \mathrm{m}^{2}(\mathrm{SD}=3.87)$. The mean BMI of medical university students was $21.95 \mathrm{~kg} / \mathrm{m}^{2}$ $(\mathrm{SD}=3.37)$ and non-medical university students was $22.49 \mathrm{~kg} / \mathrm{m}^{2}(\mathrm{SD}=4.26)$. 
Table 1. Demographic characteristics of participants.

\begin{tabular}{llll}
\hline Variables & & Number & $\%$ \\
\hline \multirow{3}{*}{ Sample } & Participants & 1323 & 100 \\
& Female & 1021 & 77.17 \\
& Male & 297 & 22.45 \\
& Did not specify gender & 5 & 0.38 \\
BMI category & Underweight (BMI $\left.<18.5 \mathrm{~kg} / \mathrm{m}^{2}\right)$ & 154 & 11.64 \\
& Normal weight $\left(\mathrm{BMI} 18.5-25 \mathrm{~kg} / \mathrm{m}^{2}\right)$ & 927 & 70.07 \\
& Overweight $\left(\mathrm{BMI} 25-30 \mathrm{~kg} / \mathrm{m}^{2}\right)$ & 188 & 14.21 \\
University & Obese (BMI $\left.\leq 30 \mathrm{~kg} / \mathrm{m}^{2}\right)$ & 54 & 4.08 \\
& MUS & 630 & 47.62 \\
& NMUS & 693 & 52.38 \\
& 1st & 442 & 33.4 \\
Year of study & 2nd & 241 & 18.22 \\
& 3rd & 207 & 15.65 \\
& 4th & 207 & 15.65 \\
& 5th & 177 & 13.38 \\
\hline
\end{tabular}

Abbreviations: MUS-medical university students, NMUS—non-medical university students.

3.2. Results from International Physical Activity Questionnaire-Short Form

The results from the IPAQ-SF questionnaire are presented in Table 2.

Table 2. IPAQ-SF results.

\begin{tabular}{lcccc}
\hline Type of Activity & & Females & Males & Total \\
\hline \multirow{3}{*}{ VPA } & Days/week & $1.81 \pm 1.75$ & $2.06 \pm 1.88$ & $1.87 \pm 1.78$ \\
& Min/week & $71.06 \pm 101.59$ & $112.48 \pm 161.63$ & $80.49 \pm 119.11$ \\
& MET/week & $565.19 \pm 812.7$ & $899.85 \pm 1293.07$ & $640.6 \pm 952.86$ \\
\hline \multirow{3}{*}{ MPA } & Days/week & $2.14 \pm 1.81$ & $2.31 \pm 2.01$ & $2.18 \pm 1.86$ \\
& Min/week & $72.53 \pm 93.44$ & $106.99 \pm 162.67$ & $80.3 \pm 113.73$ \\
\hline \multirow{3}{*}{ Walking } & MET/week & $290.12 \pm 373.77$ & $427.97 \pm 650.7$ & $321.18 \pm 454.92$ \\
& Days/week & $4.07 \pm 2.15$ & $4.08 \pm 2.17$ & $4.07 \pm x$ \\
All PA & Min/week & $157.79 \pm 174.39$ & $180.16 \pm 215.02$ & $162.83 \pm 184.56$ \\
& MET/week & $520.72 \pm 575.46$ & $594.52 \pm 709.58$ & $537.35 \pm 609.05$ \\
\hline Sitting time & Days/week & $8.02 \pm 4.33$ & $8.44 \pm 4.81$ & $8.11 \pm 4.44$ \\
\hline \multirow{3}{*}{} & Min/week & $300.97 \pm 276.03$ & $399.63 \pm 447.47$ & $323.20 \pm 325.33$ \\
& MET/week & $1376.03 \pm 1376.03$ & $1922.35 \pm 221.36$ & $1499.14 \pm 1579.21$ \\
\hline
\end{tabular}

Abbreviations: VPA—vigorous physical activity, MPA—moderate physical activity.

Due to a scoring protocol, IPAQ-SF participants were divided into three categories of PA: high, moderate, and low, as presented in Table 3. 
Table 3. Physical activity categories based on IPAQ-SF scoring protocol; MUS—medical university students, NMUS-non-medical university students.

\begin{tabular}{lccc}
\hline Group of Students & Low & Moderate & High \\
\hline Males: MUS & $18(17.65 \%)$ & $54(52.94 \%)$ & $30(29.41 \%)$ \\
\hline Males: NMUS & $58(29.74 \%)$ & $78(40.00 \%)$ & $59(30.26 \%)$ \\
\hline Females: MUS & $161(32.59 \%)$ & $226(45.75 \%)$ & $107(21.66 \%)$ \\
\hline Females: NMUS & $123(23.34 \%)$ & $280(53.13 \%)$ & $124(23.53 \%)$ \\
\hline Did not specify gender & $0(0 \%)$ & $4(80 \%)$ & $1(20 \%)$ \\
\hline Total & $360(27.21 \%)$ & $642(48.53 \%)$ & $324(24.26 \%)$ \\
\hline
\end{tabular}

Abbreviations: MUS-medical university students, NMUS—non-medical university students.

\subsection{Dietary Habits Results}

The frequency of the particular answers to diet-related questions is shown in Table 4 .

Table 4. Incidence within a week (\% of responders) of particular dietary habits during COVID-19 pandemic.

\begin{tabular}{|c|c|c|c|c|}
\hline & $\begin{array}{l}\text { Once a Week or } \\
\text { Less Often (\%) }\end{array}$ & $\begin{array}{l}2-3 \text { Times Per } \\
\text { Week }(\%)\end{array}$ & $\begin{array}{l}\text { Majority of Days } \\
\text { within a Week } \\
(\%)\end{array}$ & Everyday (\%) \\
\hline $\begin{array}{l}\text { Consuming more meals per day than } \\
\text { before the pandemic } \\
\text { (including snacking): }\end{array}$ & 42.86 & 26.98 & 22.68 & 7.48 \\
\hline $\begin{array}{l}\text { Consuming less than } 3 \text { servings of } \\
\text { wholegrain products daily (less } \\
\text { than } 90 \mathrm{~g} / \text { day): }\end{array}$ & 40.8 & 27.7 & 22.4 & 9.2 \\
\hline $\begin{array}{l}\text { Consuming less than } 400 \mathrm{~g} \\
\text { vegetables and fruits: }\end{array}$ & 34.0 & 30.5 & 22.7 & 12.8 \\
\hline $\begin{array}{l}\text { Consuming less than } 2 \text { glasses of } \\
\text { unsweetened milk or other } \\
\text { dairy products daily: }\end{array}$ & 38.9 & 24.8 & 19.7 & 16.7 \\
\hline $\begin{array}{l}\text { Consuming products containing } \\
\text { processed meat, such as sausages, } \\
\text { ham, frankfurters, etc.: }\end{array}$ & 43.5 & 27.7 & 19.1 & 9.8 \\
\hline $\begin{array}{l}\text { Replacing meat with protein-rich } \\
\text { plant products such as nuts and } \\
\text { legumes: beans, chickpeas, soy, lentils, } \\
\text { fava beans, peas: }\end{array}$ & 51.9 & 21.5 & 15.4 & 11.2 \\
\hline $\begin{array}{l}\text { Consuming products that are } \\
\text { sources of animal fats or trans fatty } \\
\text { acids present in products, such as } \\
\text { pastries, candy bars, salty snacks, } \\
\text { and fast-food products: }\end{array}$ & 31.6 & 36.9 & 22.1 & 9.5 \\
\hline $\begin{array}{l}\text { Consuming products that are } \\
\text { sources of unsaturated fatty acids, } \\
\text { such as canola oil, olive oil, or fish: }\end{array}$ & 20.1 & 38.0 & 29.2 & 12.7 \\
\hline $\begin{array}{l}\text { Drinking sweetened beverages } \\
\text { or fruit juices instead of water: }\end{array}$ & 20.1 & 38.0 & 29.2 & 12.7 \\
\hline Adding salt to meals: & 41.5 & 24.3 & 20.0 & 14.3 \\
\hline $\begin{array}{l}\text { Consuming meals while looking } \\
\text { at the screen of a TV, computer, or } \\
\text { other device: }\end{array}$ & 9.6 & 17.0 & 34.2 & 39.2 \\
\hline $\begin{array}{l}\text { Paying attention to labels of } \\
\text { chosen products during shopping, } \\
\text { taking into account ingredients, } \\
\text { amount of calories, etc. }\end{array}$ & 36.5 & 20.4 & 23.0 & 20.1 \\
\hline
\end{tabular}




\subsection{Results of Self-Opinion Questions}

3.4.1. Results of Self-Opinion Question on Physical Activity

In summary, $71.94 \%$ of participants noticed a negative impact of the pandemic on their PA (answers from -5 to 0 ), $8.16 \%$ no effect (answer 0 ), and $19.9 \%$ a positive impact (answers from 0 to +5 ). A total of $25.85 \%$ of them estimated that the pandemic influenced their lifestyle in the worst possible way (answer -5). All data are presented in Figure 2. Independently of the year of study, students reported a comparably negative impact of the pandemic on their PA, as shown in Figure $3 a$ (usage of Figure $3 b$ is explained later in the Section 3.4.2).

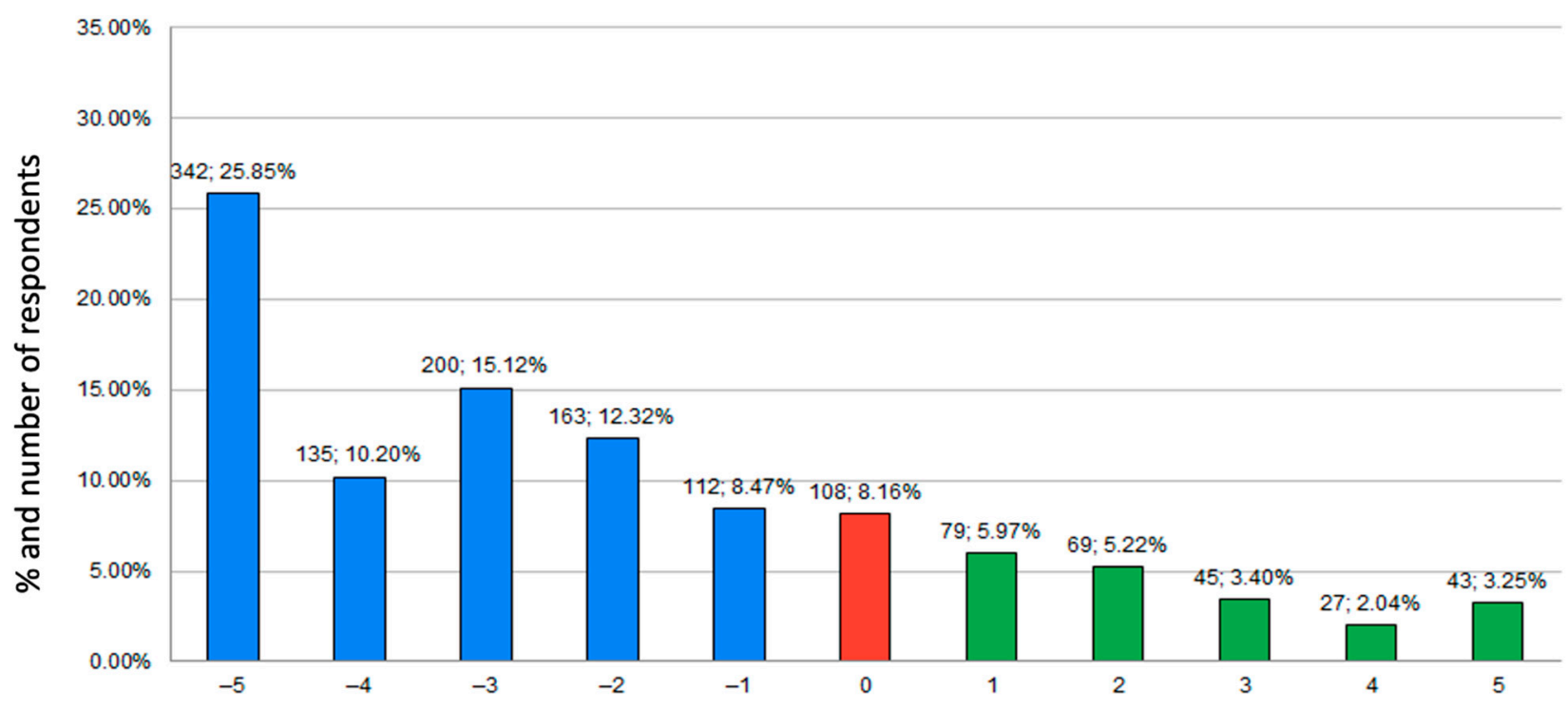

\section{Answers in $-5 / 0 /+5$ question}

Figure 2. Answers to self-opinion questions on physical activity expressed in number of participants and percentages.

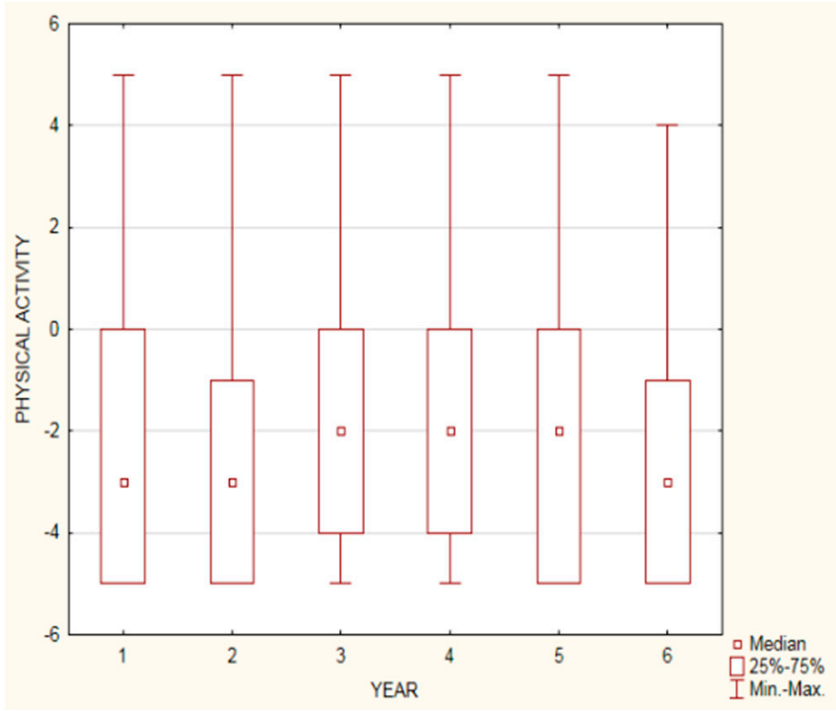

(a)

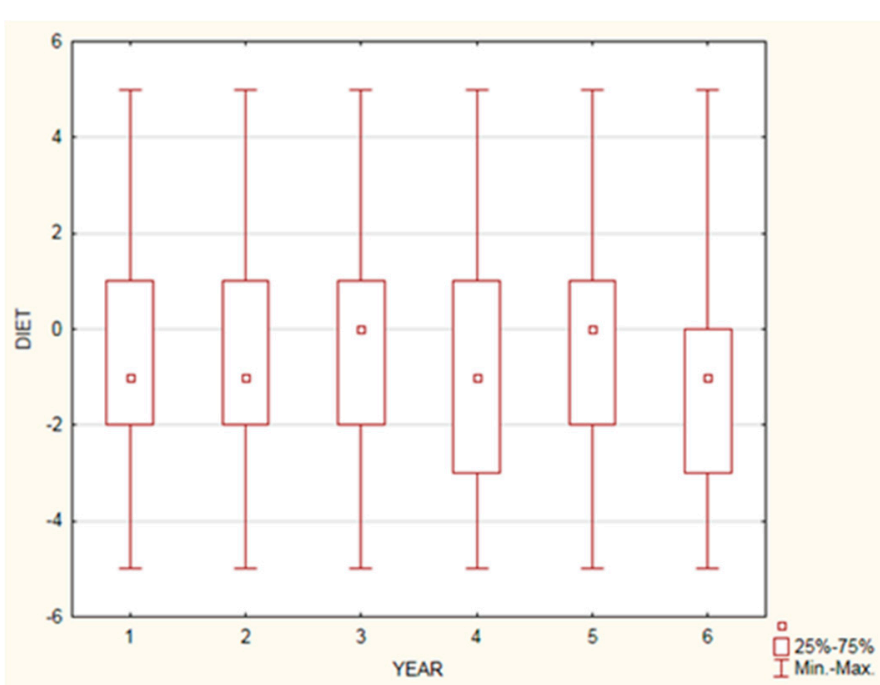

(b)

Figure 3. Results of self-opinion question depending on year of study on physical activity (a) and dietary habits (b): $x$-year of study, y-chosen answer (scale $-5,0,+5)$. 


\subsubsection{Results of Self-Opinion Question on Dietary Habits}

A total of $51.02 \%$ of the respondents assessed the impact of the COVID-19 pandemic on their dietary habits as negative (answers from -5 to 0 ), $20.11 \%$ considered that it has had no impact (answer 0 ), and $28.87 \%$ associated lockdown with a positive effect (answers from 0 to +5 ) on their nutritional behaviours. Answers on data on self-opinion questions are presented in Figure 4. Irrespective of the year of study, respondents declared a similar (moderately negative) impact of the COVID-19 pandemic on their dietary habits (data presented in Figure 3b).

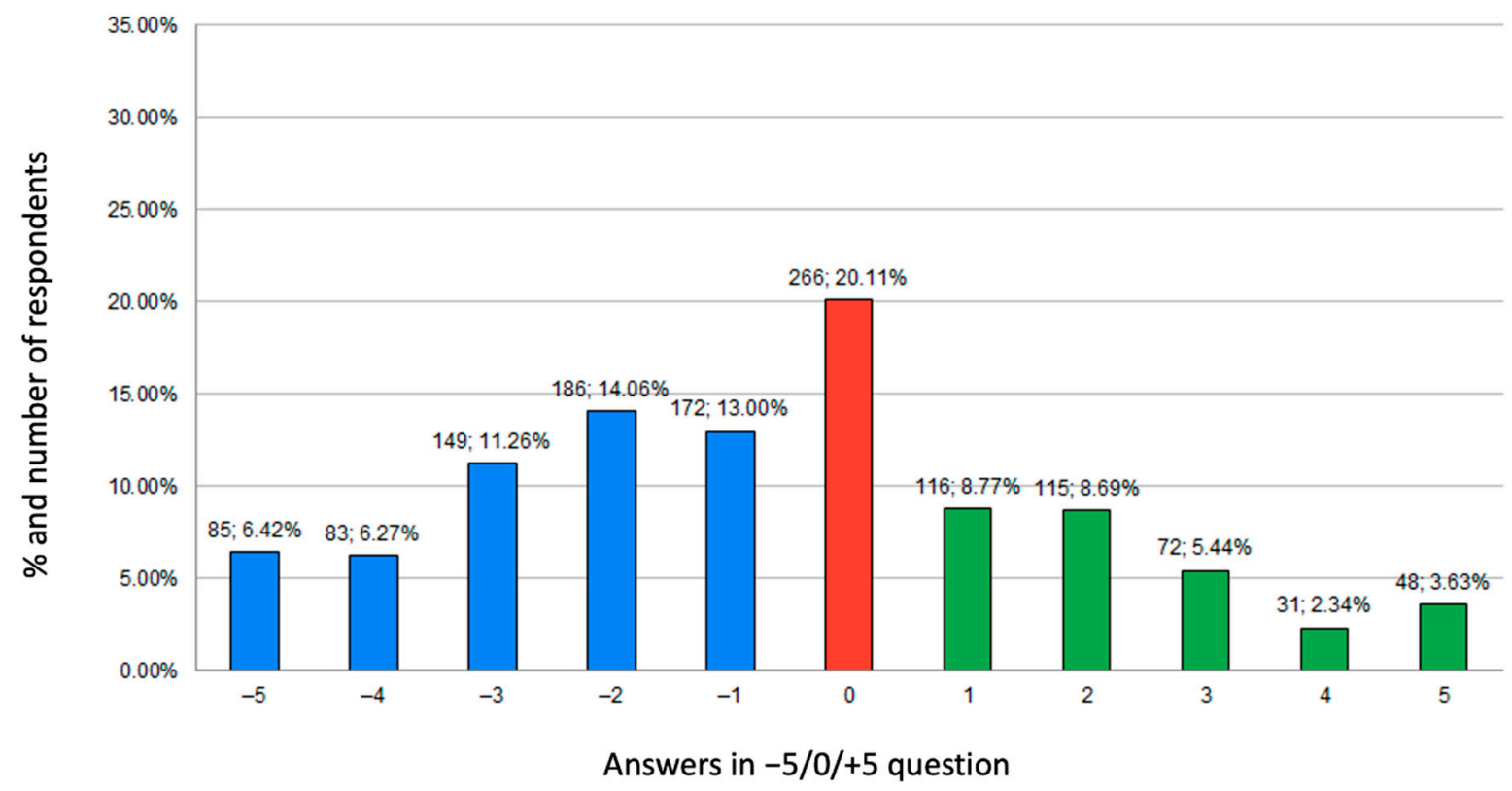

Figure 4. Answers to self-opinion question about dietary habits expressed in number of participants and percentages.

\subsection{Correlations}

Statistical correlations obtained in the research are presented in Table 5. In the two right-end columns, additional information about the test score, odds ratio, and confidence interval is shown.

Table 5. Correlations.

\begin{tabular}{lccc}
\hline Type of Variable & Higher BMI & Studying at MU & $\begin{array}{c}\text { Lower Score in PA } \\
\text { Self-Opinion Question }\end{array}$ \\
\hline Lower level of PA & $p=0.017$ & - & $p<0.001 ; \mathrm{r}=0.4 ; \mathrm{Rho}=0.435$ \\
\hline Higher level of PA & - & - & - \\
\hline $\begin{array}{l}\text { Consumption of more meals } \\
\text { before pandemic per day }\end{array}$ & $p<0.001$ & - \\
\hline $\begin{array}{l}\text { Higher consumption of } \\
\text { animal fats or trans fatty acids }\end{array}$ & $p=0.003$ & - \\
\hline $\begin{array}{l}\text { More frequent replacement of } \\
\text { water with sweetened } \\
\text { beverages or fruit juices }\end{array}$ & $p=0.014$ & - \\
\hline $\begin{array}{l}\text { More frequent attention paid } \\
\text { to labels of products and their } \\
\text { caloric intake }\end{array}$ & - & $\begin{array}{l}p<0.001 ; \mathrm{OR}=1.784 ; \\
95 \% \mathrm{Cl}=1.432-2.222\end{array}$ \\
\hline
\end{tabular}


Table 5. Cont.

\begin{tabular}{lccc}
\hline Type of Variable & Higher BMI & Studying at MU & $\begin{array}{c}\text { Lower Score in PA } \\
\text { Self-Opinion Question }\end{array}$ \\
\hline $\begin{array}{l}\text { Less frequent consumption of } \\
\text { processed meat products }\end{array}$ & - & $\begin{array}{l}p<0.001 ; \mathrm{OR}=0.544 ; \\
95 \% \mathrm{Cl}=0.426-0.695\end{array}$ & - \\
\hline $\begin{array}{l}\text { Less frequent consumption of } \\
\text { animal fats and trans fatty } \\
\text { acid sources }\end{array}$ & - & $\begin{array}{l}p=0.007 ; \mathrm{OR}=0.727 ; \\
95 \% \mathrm{Cl}=0.575-0.919\end{array}$ \\
\hline $\begin{array}{l}\text { More frequent replacements } \\
\text { of animal protein sources with } \\
\text { plant-based equivalents }\end{array}$ & - & $\begin{array}{l}p<0.001 ; \mathrm{OR}=1.736 ; \\
95 \% \mathrm{Cl}=1.357-2.221\end{array}$ \\
\hline $\begin{array}{l}\text { Less frequent drinking of } \\
\text { sweetened beverages or fruit } \\
\text { juices instead of water }\end{array}$ & - & $\begin{array}{l}p<0.001 ; \mathrm{OR}=0.331 ; \\
95 \% \mathrm{Cl}=0.24-0.455\end{array}$ \\
\hline $\begin{array}{l}\text { Less frequent consumption of } \\
\text { less than } 400 \mathrm{~g} \text { vegetables and } \\
\text { fruits per day }\end{array}$ & - & $\begin{array}{l}p=0.019 ; \mathrm{OR}=0.763 ; \\
95 \% \mathrm{Cl}=0.608-0.957\end{array}$ \\
\hline
\end{tabular}

Abbreviations: MU—medical university; PA—physical activity.

\subsection{Summary of Differences in Results between Medical and Non-Medical Students}

According to the results, medical university students paid more attention to their nutrition and physical activity. In comparison to non-medical university students, they statistically more often paid attention to labels of chosen products during shopping and took ingredients and the amount of calories into account. They consumed processed meat products and those that are a source of animal fats or trans fatty acids less often and replaced them with protein-rich plant products more often. They drank sweetened beverages or fruit juices instead of water and consumed less than $400 \mathrm{~g}$ of vegetables and fruits statistically less often. They also achieved higher values of MET-min/week values.

\section{Discussion}

Subjective assessment of the lifestyle habits of the participants revealed that the pandemic had a negative impact on their PA and nutrition. A total of $71.94 \%$ of them estimated the effect of the pandemic on their PA as negative (answers from -5 to -1 ). This was correlated with lower PA levels determined by IPAQ-SF. Students spent most of the day sitting. Previous studies show that the restrictions have reduced overall PA (number of days and number of hours) and access to exercise [9]. The decrease in the PA level might have been affected by different factors. The closure of gyms, fitness clubs, and swimming pools caused a significant decrease in exercise possibilities. It was previously reported that participation in sports clubs had an important position in PA promotion for younger populations and that sports club participants were more likely to meet PA recommendations [38]. Additionally, our study was conducted during winter and early spring, when the weather conditions were poor and possibilities of outdoor activities were limited. According to the results, students spent most of the day sitting, likely due to the increased time that people were required to stay within their quarantine location [9]. Universities transitioned to online learning and many places of students' part-time jobs have been closed. These factors forced them to stay at home and could have caused an increase in sedentary behaviour.

There was a statistical correlation between lower MET-min/week values and a higher amount of sitting time. Lower PA is associated with a higher risk of all-cause mortality and hypertension, which is a key factor in cardiovascular disease [25]. There is a correlation between lower PA levels and a higher incidence of type 2 diabetes. Remaining physically active reduces symptoms of anxiety and depression and positively impacts cognitive health and sleep. Higher amounts of sedentary behaviour are connected with a higher 
risk of all-cause mortality, cardiovascular disease mortality, and the incidence of type 2 diabetes [25].

In our study, we investigated whether students' dietary choices were compatible with "Healthy Nutrition Recommendations" developed by the National Institute of Hygiene [35]. We found that more than one-third of the study population (35.5\%) had an insufficient intake of fruits and vegetables (less than $400 \mathrm{~g}$ per day) on most days of the week or every day. The importance of meeting this requirement and its function in preventing CVD diseases were observed in previous studies [39,40]. Only $12.7 \%$ of respondents reported that they consume sources of unsaturated fatty acids every day, while $22.1 \%$ of them declared eating products that are sources of animal fats on the majority of days within a week, and 9.5\% every day. Guidelines emphasise that the consumption of animal sources of fat should be replaced by consuming vegetable oils. An improper balance of saturated and unsaturated fatty acids consumption poses a risk of the aggravation of dyslipidaemia and can increase the risk for a severe course of COVID-19 and disease mortality [41]. More than one-third of the responders (34.3\%) declared adding salt to meals on the majority of days within a week or every day. A high salt content in the diet can result in developing hypertension. Many guidelines recommend reducing salt intake by avoiding adding additional salt to meals and reducing the consumption of processed foods such as meat products and salted snacks [42-44]. Negative changes in eating behaviours could be attributed to mood-driven eating (e.g., out of anxiety or boredom) and a dip in motivation to participate in PA or maintain healthy eating [9]. Acute and chronic stress is connected with impulsive, rewarding behaviour, such as overeating [15]. The high amount of students with an insufficient intake of fruits and a high intake of products that are sources of animal fats may be associated with the winter-spring season, when people generally consume food containing more calories [45]. It should be emphasised that even before the pandemic, university students' dietary habits were far from being compliant with the nutritional recommendations for fruit, vegetables, and sodium intake [46].

An interesting finding from our study is that medical university students seemed to pay more attention to their dietary choices and achived higher MET-min/week values. This fact could be explained by the character of their universities and their academic environment. In general, medical university students should gain more knowledge about the benefits and necessity of healthy habits. These findings are not in accordance with the results observed in previous research, which suggested that the highest level of knowledge on food and nutrition was not connected with a healthier diet [16,17]. Other studies revealed that even students from medical and nutritional university departments showed inadequate awareness on healthy eating habits [16] and did not fulfil the PA and nutritional recommendations [19].

We found some correlations between PA and BMI as well as between nutrition and BMI. Participants with a higher BMI had a lower PA level, consumed more meals per day than before the pandemic, consumed products that are a source of animal fats or trans fatty acids more often, and replaced water with sweetened beverages or fruit juices more often. The correlation between a higher BMI and poorer dietary choices was also found in a different study among adults in Poland [47]. Obesity is often considered to be a result of either excessive food intake or of insufficient physical activity [48]. Matching energy intake to a level of energy expenditure is an important strategy to maintain a healthy weight [48]. There is a great need to evaluate the potential impact of teaching young populations about energy balance (i.e., how energy in food interacts with energy expenditure to determine body weight) and about how food and physical activity choices impact energy balance [48].

Pre-pandemic studies show that university students did not fulfil the recommendations for PA and nutrition before [20]. This trend might continue and intensify. University is the last stage in young people's lives, in which they have a chance to acquire proper knowledge and healthy habits before beginning an independent adult life $[49,50]$. Therefore, proper actions should be taken to encourage young people to live a healthy lifestyle [51]. 


\section{Conclusions}

A high number of Polish students did not meet nutritional recommendations. Moreover, many of them did not meet physical activity requirements described as for medium or highly active people. Most of them declared a negative impact on their PA and diet due to the COVID-19 pandemic. Effects of physical inactivity and bad dietary habits caused by the pandemic may have long-term consequences and can lead to the deterioration of health and chronic diseases.

For a better assessment of the impact of the COVID-19 pandemic on the physical activity of Polish students, more studies are needed. An in-depth analysis of these issues is necessary to evaluate and implement interventions.

\section{Limitations}

The presented study was conducted online; therefore, we cannot be sure that the responders fully understood the questions and answered them correctly. The outcomes could be affected by the fact that our form was more likely fulfilled by people interested in a healthy lifestyle. The majority of our responders were females. This could be related to the high number of females in universities in Poland [52]. In addition, women in Poland were more likely to discuss the topic of the COVID-19 pandemic on Facebook and Instagram, which were the platforms where our survey was mainly distributed [53]. The study was conducted in a relatively short period of time, during winter and early spring, which could have influenced the results of IPAQ-SF-during winter, people normally tend to participate in less sport. There is a probability that physical activity and dietary habits varied during the pandemic. In addition, data from times before restrictions were imposed were not collected. This was due to the fact that our study was conducted nearly a year after the outbreak of the pandemic and there was a high probability that the responders would not have remembered their habits after this time. To decrease the impact of the limitations, we implicated the data clinic process with the exclusion of unviable answers with a high probability of misunderstanding the questions. A limitation that must be highlighted is the fact that it was not possible to demonstrate the validity of the questionnaire through common analysis methods (i.e., using objective measures of PA from movement devices such as accelerometers or pedometers for comparison with the self-reported measures).

Supplementary Materials: The following are available online at https:/ / www.mdpi.com/article/10 .3390/ijerph18189632/s1, S1: Questionnaire form.

Author Contributions: Conceptualization, P.S.K., N.A., Z.S., A.M.J., G.G., J.G.; methodology, P.S.K., N.A., Z.S., A.M.J., G.G., J.G.; formal analysis, P.S.K., N.A., G.G.; investigation, P.S.K., N.A., Z.S., A.M.J., G.G., J.G.; data curation, P.S.K.; writing—original draft preparation, A.M.J., Z.S.; writingreview and editing, N.A., A.M.J., D.Ś., G.G.; visualization, P.S.K., A.M.J.; supervision, D.Ś., A.M.; project administration, D.Ś., A.M.J., G.G. All authors have read and agreed to the published version of the manuscript.

Funding: This research received no external funding.

Institutional Review Board Statement: The study was conducted according to the guidelines of the Declaration of Helsinki. Ethical review and approval were waived for this study due to involving only anonymous data.

Informed Consent Statement: Respondents participated voluntarily and thus filling out the questionnaire was taken as a form of consent. All participants were informed about the purpose of this study.

Data Availability Statement: The data presented in this study are available on request from the corresponding author. The data are not publicly available due to not obtaining consent from respondents for publishing the data.

Acknowledgments: For their help in statistical analysis, we would like to thank Emanuel Tataj, Department of Medical Informatics and Telemedicine, Medical University of Warsaw and Michał Możdżonek, Faculty of Mathematics and Information Science, Warsaw University of Technology. 
Conflicts of Interest: The authors declare no conflict of interest.

\section{References}

1. Regulation of the Minister of Health 1 of 20 March 2020 on the Declaration of an Epidemic in the Territory of the Republic of Poland. Available online: https:/ / dziennikustaw.gov.pl/D2020000049101.pdf (accessed on 2 August 2021).

2. Chu, D.K.; Akl, E.A.; Duda, S.; Solo, K.; Yaacoub, S.; Schunemann, H.J. Physical distancing, face masks, and eye protection to prevent person-to-person transmission of SARS-CoV-2 and COVID-19: A systematic review and meta-analysis. Lancet 2020, 395, 1973-1987. [CrossRef]

3. Khanna, R.C.; Cicinelli, M.V.; Gilbert, S.S.; Honavar, S.G.; Murthy, G.V. COVID-19 pandemic: Lessons learned and future directions. Indian J. Ophthalmol. 2020, 68, 703-710. [CrossRef]

4. Mattioli, A.V.; Sciomer, S.; Cocchi, C.; Maffei, S.; Gallina, S. Quarantine during COVID-19 outbreak: Changes in diet and physical activity increase the risk of cardiovascular disease. Nutr. Metab. Cardiovasc. Dis. 2020, 30, 1409-1417. [CrossRef]

5. King, A.J.; Burke, L.M.; Halson, S.L.; Hawley, J.A. The Challenge of Maintaining Metabolic Health During a Global Pandemic. Sports Med. 2020, 50, 1233-1241. [CrossRef]

6. Hossain, M.M.; Sultana, A.; Purohit, N. Mental health outcomes of quarantine and isolation for infection prevention: A systematic umbrella review of the global evidence. Epidemiol. Health 2020, 42, e2020038. [CrossRef]

7. Magdalena Górnicka, M.E.D.; Zielinska, M.A.; Hamułka, J. Dietary and lifestyle changes during COVID-19 and the subsequent lockdowns among polish adults: A cross-sectional online survey PLifeCOVID-19 study. Nutrients 2020, 12, 2324. [CrossRef] [PubMed]

8. Gjaka, M.; Feka, K.; Bianco, A.; Tishukaj, F.; Giustino, V.; Parroco, A.M.; Palma, A.; Battaglia, G. The Effect of COVID-19 Lockdown Measures on Physical Activity Levels and Sedentary Behaviour in a Relatively Young Population Living in Kosovo. J. Clin. Med. 2021, 10, 763. [CrossRef]

9. Ammar, A.; Brach, M.; Trabelsi, K.; Chtourou, H.; Boukhris, O.; Masmoudi, L.; Bouaziz, B.; Bentlage, E.; How, D.; Ahmed, M.; et al. Efects of COVID-19 Home Confinement on Eating Behaviour and Physical Activity: Results of the ECLB-COVID19 International Online Survey. Nutrients 2020, 12, 1583. [CrossRef]

10. Opez-Valenciano, A.; Suarez-Iglesias, D.; Sanchez-Lastra, M.A.; Ayan, C. Impact of COVID-19 pandemic on university students physical activity levels: An early systematic review. Front. Psychol. 2020, 11, 624567. [CrossRef]

11. Luciano, F.; Cenacchi, V.; Vegro, V.; Pavei, G. COVID-19 lockdown: Physical activity, sedentary behaviour and sleep in Italian medicine students. Eur. J. Sport Sci. 2020, 6, 1-10. [CrossRef] [PubMed]

12. Błaszczyk-Bębenek, E.; Jagielski, P.; Bolesławska, I.; Jagielska, A.; Nitsch-Osuch, A.; Kawalec, P. Nutrition Behaviors in Polish Adults before and during COVID-19 Lockdown. Nutrients 2020, 12, 3084. [CrossRef] [PubMed]

13. Robinson, E.; Boyland, E.; Chisholm, A.; Harrold, J.; Maloney, N.G.; Marty, L.; Mead, B.R.; Noonan, R.; Hardman, C.A. Obesity, eating behavior and physical activity during COVID-19 lockdown: A study of UK adults. Appetite 2021, 156, 104853. [CrossRef]

14. Barrington, W.E.; Beresford, S.A.; McGregor, B.A.; White, E. Perceived stress and eating behaviors by sex, obesity status, and stress vulnerability: Findings from the vitamins and lifestyle (VITAL) study. J. Acad. Nutr. Diet. 2014, 114, 1791-1799. [CrossRef]

15. Cotter, E.W.; Kelly, N.R. Stress-related eating, mindfulness, and obesity. Health Psychol. 2018, 37, 516-525. [CrossRef]

16. Antonopoulou, M.M.; Maria, M.; Serdari, A.; Bonotis, K.; Vasios, G.; Pavlidou, E.; Trifonos, C. Evaluating Mediterranean diet adherence in university student populations: Does this dietary pattern affect students' academic performance and mental health? Int. J. Health Plann. Manag. 2020, 35, 5-21. [CrossRef] [PubMed]

17. Suliga, E.; Ciesla, E.; Michel, S.; Kaducakova, H.; Martin, T.; Sliwinski, G.; Braun, A.; Izova, M.; Lehotska, M.; Koziel, D.; et al. Diet Quality Compared to the Nutritional Knowledge of Polish, German, and Slovakian University Students-Preliminary Research. Int. J. Environ. Res. Public Health 2020, 17, 9062. [CrossRef]

18. Morinaka, T.; Wozniewicz, M.; Jeszka, J.; Bajerska, J.; Nowaczyk, P.; Sone, Y. Westernization of dietary patterns among young Japanese and Polish females-A comparison study. Ann. Agric. Environ. Med. 2013, 20, 122-130.

19. Likus, W.; Milka, D.; Bajor, G.; Jachacz-Lopata, M.; Dorzak, B. Dietary habits and physical activity in students from the Medical University of Silesia in Poland. Rocz. Panstw. Zakl. Hig. 2013, 64, 317-324.

20. Aceijas, C.W.; Waldhäusl, S.; Lambert, N.; Cassar, S.; Bello-Corassa, R. Determinants of health-related lifestyles among university students. Perspect. Public Health 2017, 137, 227-236. [CrossRef] [PubMed]

21. Grasdalsmoen, M.; Eriksen, H.R.; Lonning, K.J.; Sivertsen, B. Physical exercise and body-mass index in young adults: A national survey of Norwegian university students. BMC Public Health 2019, 19, 1354. [CrossRef]

22. Budzynski-Seymour, E.C.; Conway, R.; Wade, M.; Lucas, A.; Jones, M.; Mann, S.; Steele, J. Physical activity, mental and personal well-being, social isolation, and perceptions of academic attainment and employability in university students: The scottish and british active students surveys. J. Phys. Act. Health 2020, 17, 610-620. [CrossRef]

23. Warburton, D.E.R.; Bredin, S.S.D. Health benefits of physical activity: A systematic review of current systematic reviews. Curr. Opin. Cardiol. 2017, 32, 541-556. [CrossRef] [PubMed]

24. Galbete, C.; Schwingshackl, L.; Schwedhelm, C.; Boeing, H.; Schulze, M.B. Evaluating Mediterranean diet and risk of chronic disease in cohort studies: An umbrella review of meta-analyses. Eur. J. Epidemiol. 2018, 33, 909-931. [CrossRef] [PubMed] 
25. Fiona Bull, J.W.; Baltag, V.; Bucagu, M.; Butchart, A.; Chowdhary, N.; Guthold, R.; Hämäläinen, R.-M.; Ilbawi, A.; Khan, W.; Lee, L.; et al. WHO Guidelines on Physical Activity and Sedentary Behaviour. 2020. Available online: https://www.who.int/ publications/i/item/9789240015128 (accessed on 2 August 2021).

26. Tabish, S.A. Lifestyle diseases: Consequences, characteristics, causes and control. J. Cardiol. Curr. Res. 2017, 9, 000326.

27. Schlesinger, S.; Neuenschwander, M.; Ballon, A.; Nöthlings, U.; Barbaresko, J. Adherence to healthy lifestyles and incidence of diabetes and mortality among individuals with diabetes: A systematic review and meta-analysis of prospective studies. J. Epidemiol. Community Health 2020, 74, 481-487. [CrossRef]

28. Nyberg, S.T.; Singh-Manoux, A.; Pentti, J.; Madsen, I.E.H.; Sabia, S.; Alfredsson, L.; Bjorner, J.B.; Borritz, M.; Burr, H.; Goldberg, M.; et al. Association of healthy lifestyle with years lived without major chronic diseases. JAMA Intern. Med. 2020, 180, 760-768. [CrossRef]

29. Hamer, M.K.; Kivimäki, M.; Gale, C.R.; Batty, G.D. Lifestyle risk factors, inflammatory mechanisms, and COVID-19 hospitalization: A community-based cohort study of 387,109 adults in UK. Brain Behav. Immun. 2020, 87, 184-187. [CrossRef]

30. Finkelstein, E.A.; Khavjou, O.A.; Thompson, H.; Trogdon, J.G.; Pan, L.; Sherry, B.; Dietz, W. Obesity and severe obesity forecasts through 2030. Am. J. Prev. Med. 2012, 42, 563-570. [CrossRef]

31. Nina Roth, C.K.; Afezolli, M.; Casals Alis, J.M.; Basilisian, M.; Bagyrova, B.; Wagner, F.; Kolomiets, N.; van Havere, R.J.L.; Filipovic-Hadziomeragic, A.; Jusupovic, F.; et al. Food Based Dietary Guidelines in the WHO European Region, in WHO Regional Office for Europe; World Health Organization: Geneva, Switzerland, 2003; p. 5.

32. Zatonska, K.; Psikus, P.; Basiak-Rasala, A.; Stepnicka, Z.; Gawel-Dabrowska, D.; Wolyniec, M.; Gibka, J.; Szuba, A.; PoltynZaradna, K. Obesity and chosen non-communicable diseases in pure Poland cohort study. Int. J. Environ. Res. Public Health 2021, 18, 2701. [CrossRef]

33. Guthold, R.; Stevens, G.A.; Riley, L.M.; Bull, F.C. Worldwide trends in insufficient physical activity from 2001 to 2016 : A pooled analysis of 358 population-based surveys with 1.9 million participants. Lancet Glob. Health 2018, 6, e1077-e1086. [CrossRef]

34. Lee, P.H.; Macfarlane, D.J.; Lam, T.H.; Stewart, S.M. Validity of the International Physical Activity Questionnaire Short Form (IPAQ-SF): A systematic review. Int. J. Behav. Nutr. Phys. Act. 2011, 8, 115. [CrossRef] [PubMed]

35. National Center for Nutritional Education- Healthy Eating Recommendations. Available online: https://ncez.pzh.gov.pl/abczywienia/talerz-zdrowego-zywienia/ (accessed on 3 August 2021).

36. IPAQ Scoring Protocole. Available online: https://sites.google.com/site/theipaq/scoring-protocol (accessed on 3 August 2021).

37. Byrne, N.M.; Hills, A.P.; Hunter, G.R.; Weinsier, R.L.; Schutz, Y. Metabolic equivalent: One size does not fit all. J. Appl. Physiol. 2005, 99, 1112-1119. [CrossRef]

38. Kokko, S.; Martin, L.; Geidne, S.; Van Hoye, A.; Lane, A.; Meganck, J.; Scheerder, J.; Seghers, J. Does sports club participation contribute to physical activity among children and adolescents? A comparison across six European countries. Scand. J. Public Health 2019, 47, 851-858. [CrossRef] [PubMed]

39. He, F.J.; Nowson, C.A.; Lucas, M.; MacGregor, G.A. Increased consumption of fruit and vegetables is related to a reduced risk of coronary heart disease: Meta-analysis of cohort studies. J. Hum. Hipertens. 2007, 21, 717-728. [CrossRef]

40. Crowe, F.L.R.; Roddam, A.W.; Key, T.J.; Appleby, P.N.; Overvad, K.; Jakobsen, M.U.; Tjonneland, A.; Hansen, L.; Boeing, H.; Weikert, C.; et al. Fruit and vegetable intake and mortality from ischaemic heart disease: Results from the European Prospective Investigation into Cancer and Nutrition (EPIC)-Heart study. Eur. Heart J. 2011, 32, 1235-1243. [CrossRef]

41. Butler, M.J.; Barrientos, R.M. The impact of nutrition on COVID-19 susceptibility and long-term consequences. Brain Behav. Immun. 2020, 87, 53-54. [CrossRef] [PubMed]

42. Kłosiewicz-Latoszek, L.; Szostak, W.B.; Podolec, P.; Kopeć, G.; Pająk, A.; Kozek, E.; Naruszewicz, M.; Stańczyk, J.; Opala, G.; Windak, A.; et al. Epidemiology and prevention Polish Forum for Prevention Guidelines on Diet. Pol. Heart J. 2008, 66, 812-814.

43. Perk, J.; De Backer, G.; Gohlke, H.; Graham, I.; Reiner, Z.; Verschuren, M.; Albus, C.; Benlian, P.; Boysen, G.; Cifkova, R.; et al. European Guidelines on cardiovascular disease prevention in clinical practice (version 2012). The Fifth Joint Task Force of the European Society of Cardiology and Other Societies on Cardiovascular Disease Prevention in Clinical Practice (constituted by representatives of nine societies and by invited experts). Eur. Heart J. 2012, 33, 1635-1701.

44. McGuire, S.; U.S. Department of Agriculture and U.S. Department of Health and Human Services. Dietary Guidelines for Americans, 2010, 7th ed.; U.S. Government Printing Office: Washington, DC, USA, 2011; Volume 2, pp. 293-294.

45. Stelmach-Mardas, M.; Kleiser, C.; Uzhova, I.; Penalvo, J.L.; La Torre, G.; Palys, W.; Lojko, D.; Nimptsch, K.; Suwalska, A.; Linseisen, J.; et al. Seasonality of food groups and total energy intake: A systematic review and meta-analysis. Eur. J. Clin. Nutr. 2016, 70, 700-708. [CrossRef]

46. Rosi, A.; Paolella, G.; Biasini, B.; Scazzina, F. Dietary habits of adolescents living in North America, Europe or Oceania: A review on fruit, vegetable and legume consumption, sodium intake, and adherence to the Mediterranean Diet. Nutr. Metab. Cardiovasc. Dis. 2019, 29, 544-560. [CrossRef]

47. Sidor, A.; Rzymski, P. Dietary choices and habits during COVID-19 lockdown: Experience from Poland. Nutrients 2020, $12,1657$. [CrossRef]

48. Hill, J.O.; Wyatt, H.R.; Peters, J.C. Energy balance and obesity. Circulation 2012, 126, 126-132. [CrossRef]

49. Oyeyemi, A.L.; Muhammed, S.; Oyeyemi, A.Y.; Adegoke, B.O. Patterns of objectively assessed physical activity and sedentary time: Are Nigerian health professional students complying with public health guidelines? PLoS ONE 2017, 12, e0190124. [CrossRef] [PubMed] 
50. Kwan, M.Y.; Cairney, J.; Faulkner, G.E.; Pullenayegum, E.E. Physical activity and other health-risk behaviors during the transition into early adulthood: A longitudinal cohort study. Am. J. Prev. Med. 2012, 42, 14-20. [CrossRef]

51. Chen, P.; Mao, L.; Nassis, G.P.; Harmer, P.; Ainsworth, B.E.; Li, F. Coronavirus disease (COVID-19): The need to maintain regular physical activity while taking precautions. J. Sport Health Sci. 2020, 9, 103-104. [CrossRef]

52. Office, C.S. Higher Education in the 2020/2021 Academic Year (Preliminary Results). 2021. Available online: https://stat.gov pl/obszary-tematyczne/edukacja/edukacja/szkolnictwo-wyzsze-w-roku-akademickim-20202021-wyniki-wstepne,8,7.html (accessed on 2 August 2021).

53. Burzynska, J.; Bartosiewicz, A.; Rekas, M. The social life of COVID-19: Early insights from social media monitoring data collected in Poland. Health Inform. J. 2020, 26, 3056-3065. [CrossRef] 